\title{
Total Synthesis of Enantiopure (+)- $Y$-Lycorane Using Highly Efficient Pd-Catalyzed Asymmetric Allylic Alkylation
}

\author{
Bruno D. Chapsal and Iwao Ojima \\ Department of Chemistry, State University of New York at Stony Brook, Stony Brook, NY \\ 11794-3400
}

\section{Abstract}

Highly efficient short total synthesis of $\gamma$-lycorane (>99\% ee, $41 \%$ overall yield) was achieved by using the asymmetric allylic alkylation in the key step catalyzed by palladium complexes with novel chiral biphenol-based monodentate phosphoramidite ligands.

Catalytic asymmetric allylic substitution serves as one of the most powerful methods for the regio- and stereoselective formation of $\mathrm{C}-\mathrm{C}, \mathrm{C}-\mathrm{N}$ and $\mathrm{C}-\mathrm{O}$ bonds. The high synthetic utility of this catalytic process is now well established through numerous efficient syntheses of enantiopure natural and unnatural products. ${ }^{1}$ Trost et al. pioneered the asymmetric allylic alkylation using $\mathrm{C}_{2}$-symmetric diamine-based modular diphosphine ligands, which achieved excellent enantioselectivity in various systems. ${ }^{1-2}$ The use of chiral monodentate phosphorus ligands in catalytic asymmetric allylic alkylation has been reported with an Ir-complex precursor, which generally leads to the formation of branched products with excellent regioselectivity. ${ }^{3}$ In contrast, the corresponding Pd-catalyzed reactions with monodentate phosphorus ligands remain poorly explored. ${ }^{4}$

We have reported a new class of monodentate phosphorus ligands based on axially chiral biphenols. ${ }^{5}$ One of the salient features of these ligands is their fine-tuning capability through modification of the $\mathrm{R}^{1}, \mathrm{R}^{2}$ and $\mathrm{R}^{3}$ groups (Figure 1 ). Thus, high catalytic activity and enantioselectivity have been achieved in the hydrogenation of dimethyl itaconate (up to $99.6 \%$ ee), hydroformylation of allyl cyanide (up to $80 \%$ ee) and conjugate addition of diethylzinc to cycloalkenones and nitroolefins (up to $99 \%$ ee). ${ }^{5}$

We describe here the application of these ligands to the Pd-catalyzed asymmetric allylic alkylation reaction for the total synthesis of $(+)-\gamma$-lycorane, an alkaloid isolated from the plants of Amaryllidacae family. Because of its unique pentacyclic structure, $(+)-\gamma$-lycorane has attracted substantial attention for its total synthesis. ${ }^{6}$ However very few approaches to the asymmetric synthesis of this alkaloid have been reported so far. ${ }^{6 a, 7}$ In 1995, Mori and coworkers reported the first asymmetric synthesis of (+)- $\gamma$-lycorane, featuring a Pd-catalyzed asymmetric allylic alkylation in the key step (Scheme 1). ${ }^{7}$ However, the best enantioselectivty achieved in this key step (step i in Scheme 2) using (S)-BINAPO was $54 \%$ ee, giving 7a in $30 \%$ yield (using 2.6 equiv of $\mathbf{6}$ and LDA). The yield and enantiopuiry of $7 \mathbf{a}$ was dependent on the amounts of 6 and LDA used. Thus, $7 \mathbf{a}$ was obtained in $66 \%$ yield and $40 \%$ ee on using 1.1 equiv of 6 and LDA. This product ( $40 \%$ ee) was used to complete the total synthesis in $17 \%$ overall yield. The expedited 5-step total synthesis, incorporating one-pot protocol, gave $(+)-\gamma$-lycorane with $46 \%$ ee in $23 \%$ overall yield. 
This short total synthesis appears to have a lot of rooms for improvement. Thus, we decided to revisit this process by applying a library of our new chiral monodentate phosphoramidite ligands for optimization of the enantioselectivity and chemical yield and then accomplish a highly efficient total synthesis of $(+)-\gamma-$ lycorane.

First, we performed a model study on the desymmetrization of cis-1,4dibenzoyloxycyclohex-2-ene (1) using dibenzyl malonate as a nucleophile. The aim of this model study was the preliminary screening of effective phosphoramidite ligands. Results are summarized on Table 1.

As Table 1 shows, a substantial increase of enantioselectivity for the formation of $\mathbf{7 b}$ is observed as the size of the amine moiety of the ligand increases (entries 1 to 4 ). Thus, $\mathbf{L 1}$ afforded $\mathbf{7 b}$ with $28 \%$ ee while $81.3 \%$ ee was obtained with L5a. It is worthy of note that (i) $(S)$-biphenol-based ligands give (+)-7b as the major product, while $(R)$-biphenol-based ligands predominantly yield (-)-7b , i.e., the axial chirality of the ligand dictates the direction of the enantio-discrimination of the two benzoate groups and (ii) introduction of methyl groups at the 3,3'-positions of the biphenol moiety of $\mathbf{L 5 a}$ (i.e. $\mathbf{L 5} \mathbf{b}, \mathrm{R}^{2}=\mathrm{Me}$ ) causes a detrimental effect on the enantioselectivity as well as conversion of the reaction (entry 5). These preliminary results served as the starting point for applying our ligands to the key step in the total synthesis of enantiopure (+)- $\gamma$-lycorane.

According to our planned route to (+)- $\gamma$-lycorane by revisiting Mori's first asymmetric synthesis, it was necessary to prepare the malonate half-amide $\mathbf{6}$. Since the synthesis of $\mathbf{6}$ was not reported in Mori's paper nor anywhere else by literature search, we synthesized $\mathbf{6}$ from commercially available piperonal 2 through steps shown in Scheme 2.

Next, the efficacy of phosphoramidite ligands L3, L5a and L5b was evaluated in the reaction of $\mathbf{1}$ with "real" nucleophile $\mathbf{6}$ and LDA as base $(\mathbf{6} / \mathrm{LDA}=1)$. In consistency with the model study, L5a gave the best results among the three ligands examined. Also, it was found the solvent and the reaction temperature had critical effects on the reaction. Thus, after basic optimization of the reaction conditions using $\mathbf{L 5}$ as the ligand, the reactions in THF at $-60^{\circ}$ $\mathrm{C}$ appeared optimal. The reactions gave a 54/46 diastereomer mixture of 7a due to epimerization of the acidic methine of the malonate half amide moiety. Thus, it was necessary to convert 7a to 9 in order to determine the enantioselectivity of the reaction. The enantiopuriy of 9 was unambiguously determined by chiral HPLC analysis using a Daicel Chiralpak ADRH column (Table 2).

Under these conditions, the reaction of 1 with 6 (1.2 equiv.) using L5a gave 7a in 93\% yield and $86.2 \%$ ee (Table 2, entry 1 ). We also examined the effects of the amounts of $\mathbf{6}$ and LDA on the reaction. The reactions with 2.0 equiv and 2.6 equiv of $\mathbf{6}$ and LDA gave $7 \mathbf{a}$ with $89.5 \%$ ee (63\% yield) and $92.6 \%$ ee (27\% yield), respectively (entries 2 and 3). [Note: L6 is the enantiomer of L5a.] The results indicate that the use of excess amounts of $\mathbf{6}$ and LDA increases the enantioselectivity of the reaction. However, the observed increase in enantioselectivity is accompanied by a significant decrease in the yield of 7a. Thus, the use of 1.2 equiv. of $\mathbf{6}$ and LDA appears optimal.

Although it was already a remarkable improvement at this point that 7a was obtained in $93 \%$ isolated yield and $86.2 \%$ ee as compared with Mori's original work, ${ }^{7}$ we strongly felt that more improvement would be possible through systematic optimization of $\mathbf{L 6}$, which gives 7a that has the correct absolute configuration for the total synthesis of (+)- $\gamma-$-lycorane. Accordingly, we designed and synthesized a new optimization library of phosphoramidite ligand $\mathbf{L 6}$ by introducing various $\mathrm{C}_{2}$-symmetric, pseudo- $\mathrm{C}_{2}$-symmetric and non-symmetrical $N, N$-bis(1arylethyl)amine moieties bearing different aryl groups, including those with an ortho substituent (ligands L $\mathbf{7 - 1 4}$, Figure 1). For the introduction of ortho substituents to the $\mathrm{C}_{2}$ - and 
pseudo- $\mathrm{C}_{2}$-symmetric $N, N$-bis(1-arylethyl)amine moiety of BINOL-based phosphoramidite ligands, Alexakis recently reported the markedly favorable effects of such substituents on the enantioselectivity as well as reaction rate in his Ir-catalyzed asymmetric allylic substitution reactions. $3 \mathrm{e}$ Thus, we set out to examine the ortho substitution effect in our biphenol-based ligand - Pd-catalyst system. In addition, we designed non-symmetrical $N, N$-bis(1-arylethyl) amine moieties based on a combination of different aryl groups, i.e., phenyl, $o$-tolyl, $o$ methoxyphenyl, 1-naphthyl and 2-naphthyl groups.

The efficacy of $\mathbf{L 6}$ congeners was examined in the Pd-catalyzed reaction of $\mathbf{1}$ with $\mathbf{6}$ using [Pd (allyl)Cl $]_{2}$ and 1.2 equiv of 2 and LDA in THF at $-60{ }^{\circ} \mathrm{C}$ for $15 \mathrm{~h}$. Results are summarized in Table 2. As Table 2 shows, a very interesting and rather unanticipated substituent effect of the aryl groups of the amine moiety on the enantioselectivity as well as catalytic activity is observed. First of all, the markedly contrasting results for the use of $\mathbf{L} 7\left(\mathrm{R}^{3}=\mathrm{R}^{3^{\prime}}=1-\mathrm{Np}\right)$ and $\mathbf{L 8}\left(\mathrm{R}^{3}=\mathrm{R}^{3}=2-\mathrm{Np}\right)$ is worth mentioning (entries 4 and 5). The result for $\mathbf{L 8}(85.5 \%$ ee) is similar to that for L6 (entries 5 and 3), while the reaction with $\mathbf{L 7}$ almost did not proceed under the same conditions and no change was observed even when forcing the reaction at room temperature. Use of even one 1-naphthyl group seems to kill the Pd-catalyst activity. Thus, the reaction using $\mathbf{L 1 3}\left(\mathrm{R}^{3}=1-\mathrm{Np}, \mathrm{R}^{3}=2-\mathrm{MeO}-\mathrm{Ph}\right.$ ) virtually did not proceed (entry 10$)$. To our surprise, ligands $\mathbf{L 1 1}$ and $\mathbf{L 1 2}$, bearing $\mathrm{C}_{2}$-symmetric $N, N$-bis(1-arylethyl)amine moieties, behaved very poorly, resulting in no conversion (entry 8 ) and $<5 \%$ conversion (entry 9 ), respectively, while $\mathbf{L 9}\left(\mathrm{R}^{3}=\mathrm{Ph}, \mathrm{R}^{3}=2\right.$-tolyl) gave $83.0 \%$ ee (entry 6).

These results are unanticipated since the same amine moieties were reported to give excellent results in the Ir-catalyzed reactions with BINOL-based ligands. $3 \mathrm{e}, 3 \mathrm{f}$ Thus this reaction is found to be very sensitive to the bulkiness and arrangement of the aryl moiety at the coordination site.

A breakthrough in the enantioselectivity was achieved with ligands $\mathbf{L 1 0}\left(\mathrm{R}^{3}=\mathrm{Ph}, \mathrm{R}^{3}=2\right.$ $\mathrm{MeO}-\mathrm{Ph})$ and $\mathbf{L 1 4}\left(\mathrm{R}^{3}=1-\mathrm{Np}, \mathrm{R}^{3}=2-\mathrm{MeO}-\mathrm{Ph}\right)$, bearing non-symmetrical $N, N$-bis $(1$ arylethyl)amine moieties wherein one of the aryl groups is a 2-MeO-phenyl. The reaction with L10 and L14 gave (+)-7a with $99.7 \%$ ee (76\% yield) and $99.4 \%$ ee (83\% yield), respectively (entries 7 and 11). Both reactions reached $100 \%$ conversion in $8 \mathrm{~h}$. It appears that 2methoxyphenyl group in the non-symmetrical $N, N$-bis(1-arylethyl)amine moiety exerts a profound effect on the enantioselectivity and reaction rate. It is possible to hypothesize that the oxygen of 2-methoxylphenyl group interacts with the Pd metal to fix the orientation of the phenyl ring, which has a crucial effect on the enantio-differenciation (desymmetrization) of the two benzoate groups in meso-1. Since the isolation of 7a from the reaction mixture is very easy, the reaction with $\mathbf{L 1 4}$ provides a highly practical process for the total synthesis of enantiopure $(+)-\gamma$-lycorane.

The total synthesis of $(+)-\gamma$-lycorane was completed, following Mori's procedure with some modifications. As Scheme 3 illustrates, $(+)-7 \mathbf{a}(99.4 \%$ ee) was converted to pentacyclic oxolycorane 8 in $61 \%$ yield through one-pot tandem allylic amination - intramolecular Heck reaction. Then, $\mathbf{8}$ was subjected to the sequential demethoxycarbonylation, hydrogenation and $\mathrm{LiAlH}_{4}$-reduction to give the desired (+)- $\gamma$-lycorane (>99\% ee) in $41 \%$ overall yield (6 steps) from 1.

In conclusion, highly efficient biphenol-based monodentate phosphoramidite ligands have been developed for Pd-catalyzed asymmetric allylic alkylation. The successful total synthesis of $(+)-\gamma$-lycorane demonstrates the advantage of the facile fine-tuning capability of our novel phosphoramidite ligands in developing extremely efficient ligands for a specific asymmetric transformation through rational modification of a lead ligand. Further studies on the expansion 
of our monodentate chiral phosphorus ligand library and their applications to various catalytic asymmetric transformations are actively underway.

\section{Supplementary Material}

Refer to Web version on PubMed Central for supplementary material.

\section{Acknowledgment}

This work was supported by grants from the National Institutes of Health (NIGMS) and the National Science Foundation. Generous contribution from Mitsubishi Chemical Corporation is also gratefully aknowledged.

\section{References}

1. (a) Trost BM, Van Vranken DL. Chem. Rev 1996;96:395-422. [PubMed: 11848758]Trost, BM.; Lee, C. Catalytic Asymmetric Synthesis. 2nd ed.. Ojima, I., editor. New-York, NY: Wiley-VCH; 2000. (c) Trost BM, Crawley ML. Chem. Rev 2003;103:2921-2943. [PubMed: 12914486] (d) Trost BM. J. Org. Chem 2004;69:5813-5837. [PubMed: 15373468]

2. (a) Trost BM, Van Vranken DL, Bingel C. J. Am. Chem. Soc 1992;114:9327-9343. (b) Trost B, Tanimori S, Dunn PT. J. Am. Chem. Soc 1997;119:2735-2736. (c) Trost BM, Toste FD. J. Am. Chem. Soc 1999;121:4545-4554.

3. For a review, see (a) Takeuchi R. Synlett 2002:1954-1965. For recent publications see (b) Streiff S, Welter C, Schelwies M, Lipowsky G, Miller N, Helmchen G. Chem. Commun 2005:2957-2959. (c) Bartels B, Garcia-Yebra C, Helmchen G. Eur. J. Org. Chem 2003:1097-1103. (d) Alexakis A, Polet D. Org. Lett 2004;6:3529-3532. [PubMed: 15387540] (e) Polet D, Alexakis A. Org. Lett 2005;7:16211624. [PubMed: 15816767] (f) Leitner A, Shekhar S, Pouy MJ, Hartwig JF. J. Am. Chem. Soc 2005;127:15506-15514. [PubMed: 16262414] (g) Leitner A, Shu CT, Hartwig JF. Org. Lett 2005;7:1093-1096. [PubMed: 15760147]

4. (a) Boele MDK, Kamer PCJ, Lutz M, Spek AL, de Vries JG, van Leeuwen PWNM, van Strijdonck GPF. Chem. Eur. J 2004;10:6232-6246. (b) Tsarev VN, Lyubimov SE, Shiryaev AA, Zheglov SV, Bondarev OG, Davankov VA, Kabro AA, Moiseev SK, Kalinin VN, Gavrilov KN. Eur. J. Org. Chem 2004:2214-2222. (c) Edwards CW, Shipton MR, Alcock NW, Clase H, Wills M. Tetrahedron 2003;59:6473-6480.

5. (a) Hua Z, Vassar VC, Ojima I. Org. Lett 2003;5:3831-3834. [PubMed: 14535721] (b) Hua Z, Vassar VC, Choi H, Ojima I. Proc. Nat. Acad. Sci. U.S.A 2004;101:5411-5416. (c) Choi H, Hua Z, Ojima I. Org. Lett 2004;6:2689-2691. [PubMed: 15281745]

6. (a) Dong L, Xu Y-J, Cun L-F, Cui X, Mi A-Q, Jiang Y-Z, Gong L-Z. Org. Lett 2005;7:4285-4288. [PubMed: 16146408] (b) Jin Z. Nat. Prod. Rep 2005;22:111-126. [PubMed: 15692620] (c) Yasuhara T, Osafune E, Nishimura K, Yamashita M, Yamada K-I, Muraoka O, Tomioka K. Tetrahedron Lett 2004;45:3043-3045. (d) Shao, Z-h; Peng, F-Z.; Tu, Y-Q.; Zhang, H-b. Hecheng Huaxue 2004;12:111114. (e) Shao Z, Chen J, Huang R, Wang C, Li L, Zhang H. Synlett 2003;(14):2228-2230.

7. Yoshizaki H, Satoh H, Sato Y, Nukui S, Shibasaki M, Mori M. J. Org. Chem 1995;60:2016-2021. 
<smiles></smiles>

\section{Phosphoramidite}<smiles>[R]c1cc(C)c(C)c(-c2c([R])cc(C)c(C)c2OP(Oc2c([R])cc(C)c(C)c2C)N([C@@H](C)c2ccccc2)[C@@H](C)c2ccccc2)c1</smiles>

$(R, R, R):$ L5a $\quad \mathrm{R}=\mathrm{H}$ L5b $\quad R=M e$<smiles>Cc1ccc(OP(Oc2ccc(C)c(C)c2-c2c(C)ccc(C)c2C)N([C@@H](C)c2ccccc2)[C@H](C)c2ccccc2)c(C)c1</smiles><smiles>[R]N([R])p1oc2ccc(C)c(C)c2c2c(C)c(C)ccc2o1</smiles>

(R) : L1 R = Me (S) : L2 R = iPr<smiles>[R]c1ccccc1[C@H](C)N([C@H](C)c1ccccc1)P(Oc1ccc(C)c(C)c1C)Oc1ccc(C)c(C)c1-c1c(C)cccc1O</smiles>

$(S, S, S):$ L9 $R=M e$ L10 R = OMe<smiles>Cc1ccc(OP(Oc2ccc(C)c(C)c2C)N([C@@H](C)c2ccccc2)[C@H](C)c2ccccc2)c(-c2c(C)ccc(C)c2C)c1</smiles>

$(S, R, R):$ L3<smiles>[R]c1ccccc1[C@@H](C)N([C@H](C)c1ccccc1[R])P(Oc1cccc(C)c1C)Oc1ccc(C)c(C)c1-c1c(C)cccc1O</smiles>

$(S, S, S): L 11 R=M e$ L12 R = OMe<smiles>Cc1ccc2c(c1C)-c1c(ccc(C)c1C)OP(N(C(C)C)C(C)C)N([C@H](C)c1cccc3ccccc13)C2</smiles><smiles></smiles>

$$
(S, S, S): L 6
$$

\section{$(S, S$,}

$S, S, S): L 7 \quad$ Ar $=1-N p \quad(S, S$ $\mathrm{L} 13 \mathrm{Ar}=$ 2-MeO-Ph
S,S,S) : L8 Ar $=2-\mathrm{Np}$ $\mathrm{L} 14 \mathrm{Ar}=$ 2-MeO-Ph

Figure 1.

Phosphoramidite Ligands Library 


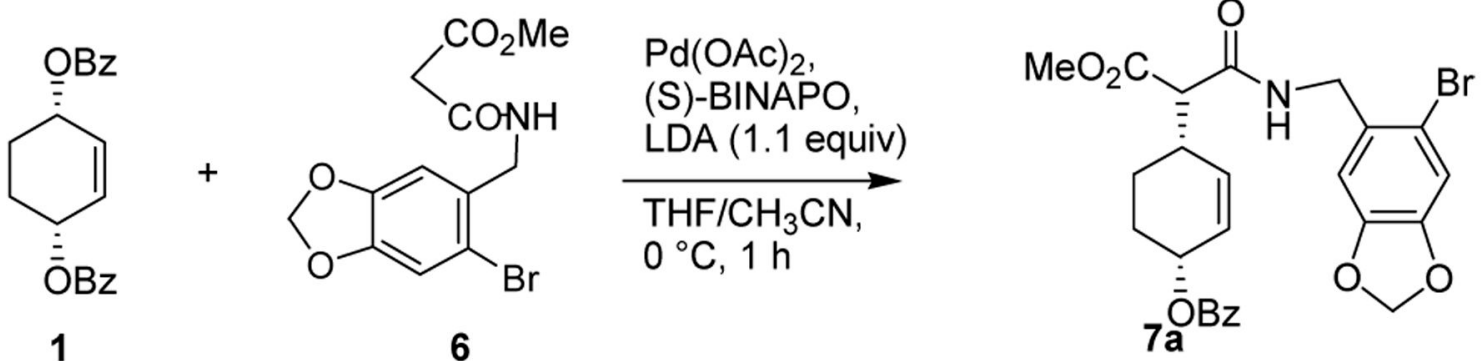

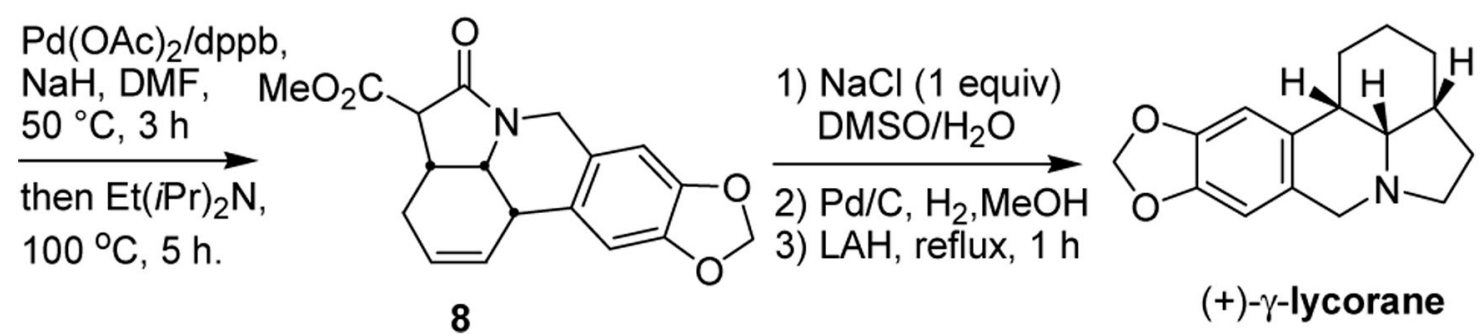

Scheme 1.

Asymmetric Synthesis of (+)- $\gamma$-lycorane 


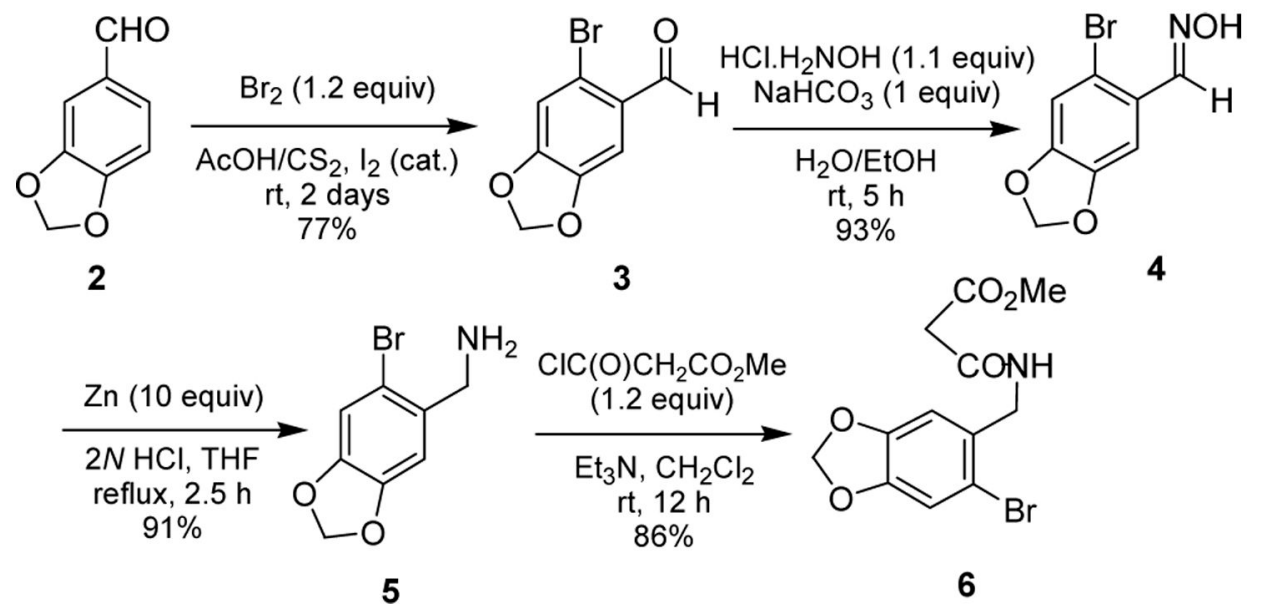

Scheme 2.

Synthesis of Nucleophile 6 
<smiles>[R16]C(C)(C)O[C@@H]1C=CC([C@@H](C(=O)NCc2cc3c(cc2Br)OCO3)C(=O)OC)CC1</smiles>

$7 a(99.4 \%$ ee $)$
1) $\mathrm{Pd}(\mathrm{OAc})_{2}(5 \mathrm{~mol} \%)$ $\mathrm{dppb}(10 \mathrm{~mol} \%)$

$\mathrm{NaH}$ (1.1 equiv) DMF, $50^{\circ} \mathrm{C}, 3 \mathrm{~h}$

2) $\mathrm{Et}(i-\mathrm{Pr})_{2} \mathrm{~N}$ (2 equiv) $110^{\circ} \mathrm{C}, 8 \mathrm{~h}$

$61 \%$ for 2 steps (one-pot)<smiles>CC1C(=O)N2Cc3cc4c(cc3[C@@H]3C=CC[C@@H]1[C@@H]32)OCO4</smiles>

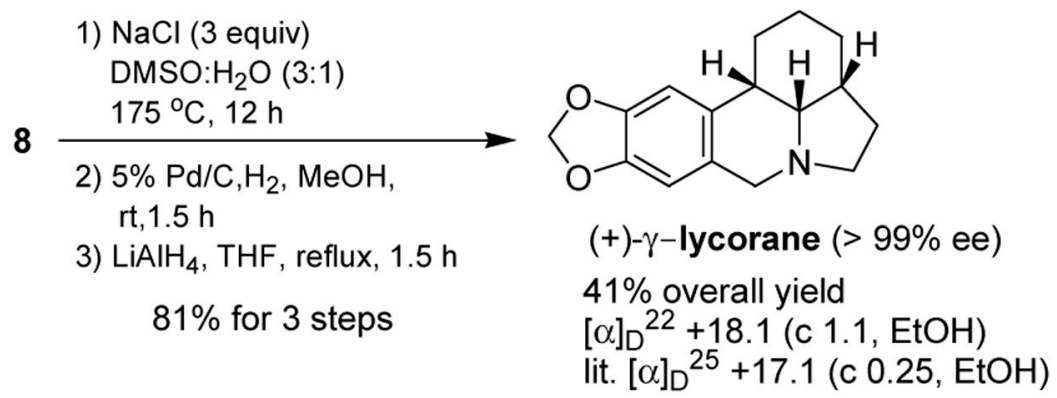

Scheme 3.

Completion of the total synthesis of $(+)-\gamma$-lycorane from $7 \mathbf{a}$ 
Table 1

Desymmetrization of meso-diester $\mathbf{1}^{a}$

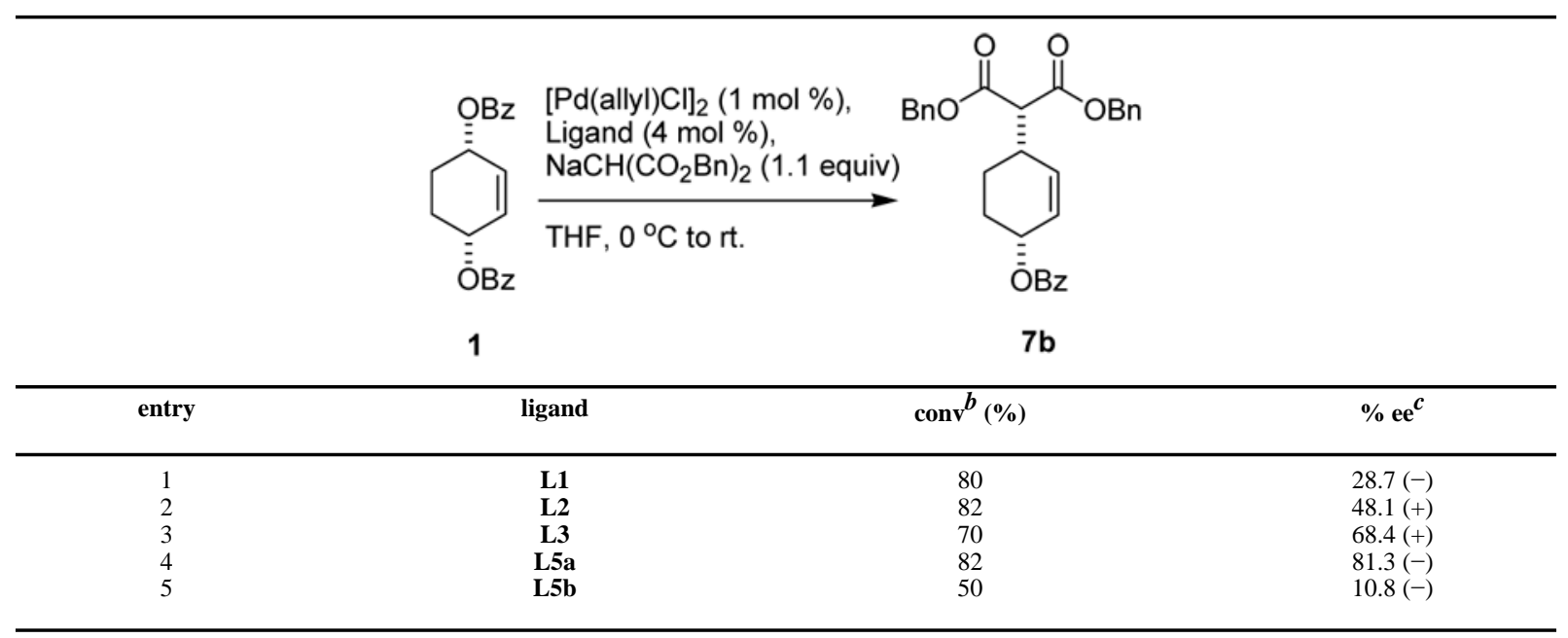

${ }_{\text {Reactions were run using }[\mathrm{Pd}(\text { alllyl }) \mathrm{Cl}] 2}(1 \mathrm{~mol} \%)$ with a monodentate ligand $(4 \mathrm{~mol} \%)$ in THF at $0{ }^{\circ} \mathrm{C}$ for $2 \mathrm{~h}$.

${ }^{b}$ Determined by ${ }^{1} \mathrm{H}-\mathrm{NMR}$.

${ }^{c}$ Determined using Daicel Chiralpak AD. 
Table 2

Pd-Catalyzed Allylic Alkylation Reaction - Desymmetrization of $\mathbf{1}$ with $\mathbf{6}^{a}$

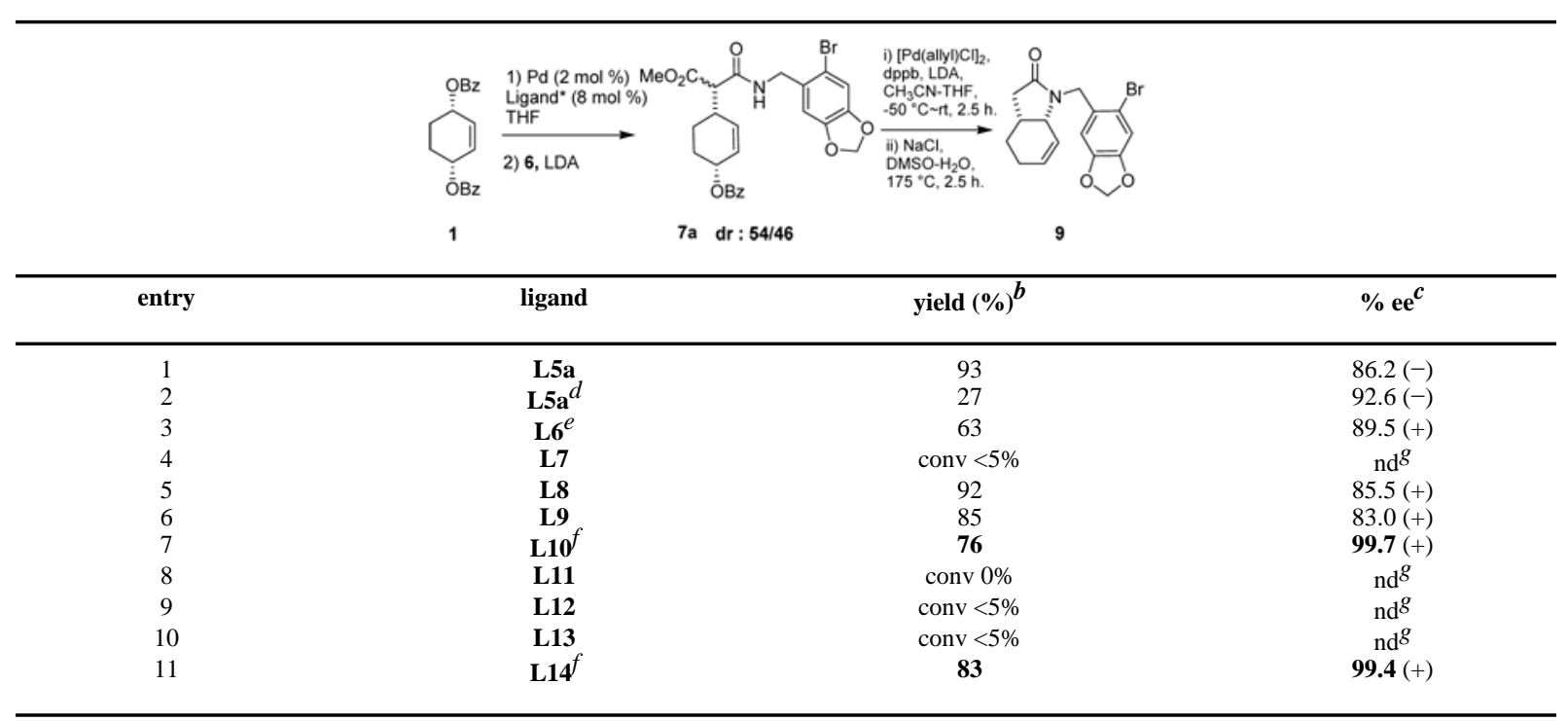

${ }^{a}$ Reactions were run with $100 \mathrm{mg}(0.31 \mathrm{mmol})$ of $\mathbf{1},\left[\mathrm{Pd}(\right.$ allyl)Cl$] 2(2 \mathrm{~mol} \%)$, a ligand $(8 \mathrm{~mol} \%), \mathbf{6}\left(1.2\right.$ equiv), LDA (1.2 equiv) in $\mathrm{THF}$ at $-60{ }^{\circ} \mathrm{C}$ for $15 \mathrm{~h}$ unless otherwised noted.

$b_{\text {Isolated yield. }}$

${ }^{c}$ Estimated based on the enantiopurity of $\mathbf{9}$ determined by chiral HPLC analysis using a Daicel Chiralpak AD-RH column.

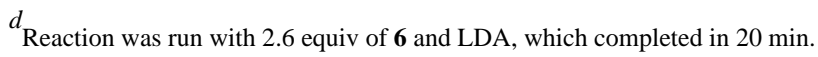

${ }^{e}$ Reaction run with 2.0 equiv of 6 and LDA.

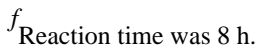

$g_{\text {nd }=\text { not determined. }}$ 